\title{
O CAMPO TÉRMICO EM ÁREA URBANA NA AMAZÔNIA BRASILEIRA: ANÁLISE EPISÓDICA NA CIDADE DE TEFÉ-AM
}

\author{
THE THERMAL FIELD IN URBAN AREAS IN THE BRAZILIAN AMAZON: EPISODE ANALYSIS IN THE CITY OF \\ TEFÉ-AM
}

\author{
Natacha Cíntia Regina Aleixo'; João Cândido André da Silva Neto \\ 1 Universidade Federal do Amazonas (UFAM), Manaus, AM, Brasil
}

Correspondência para: Natacha Cíntia Regina Aleixo (natachaaleixo@yahoo.com.br)

doi: 10.12957/geouerj.2019.40949

Recebido em: 15 ago. 2018 | Aceito em: 09 out. 2018

\section{RESUMO}

O objetivo da pesquisa foi analisar o campo térmico e as ilhas de calor em uma cidade de clima equatorial na Amazônica brasileira. O recorte espacial foi a cidade de Tefé, localizada na região do Médio Solimões no interior do estado do Amazonas. Foram realizados transectos móveis em dias representativos do mês de outubro que se insere no período sazonal menos chuvoso denominado de verão amazônico, para coleta dos dados da temperatura do ar em 37 pontos na cidade de Tefé. Os dados foram tabulados e interpolados pelo método IDW no software QGIS. Posteriormente, geraram-se as cartas da temperatura da superfície e o NDVI para análise da estrutura térmica e da densidade de vegetação na área. As diferenças térmicas entre os pontos variaram em até $4,6^{\circ} \mathrm{C}$, sendo que na área central da cidade, com ocupação mais antiga, densidade construtiva e arborização urbana esparsa, configurou-se a ilha de calor de forte magnitude. As temperaturas da superfície variaram de $25^{\circ} \mathrm{C}$ a $30^{\circ} \mathrm{C}$ e também indicaram a concentração do aquecimento na parte central, derivada da ampla cobertura de materiais construtivos inapropriados para o clima equatorial. Além disso, constatou-se que a alta densidade de vegetação arbórea associou-se a configuração da ilha de frescor. Conclui-se que os estudos de clima urbano devem ser articulados ao planejamento e (re) produção do espaço urbano, uma vez que mesmo localizada em meio a Amazônia profunda a produção social do clima urbano de forma desigual pode potencializar problemas relacionados ao desconforto térmico e a saúde de parte da população.

Palavras-chave: Clima urbano. Temperatura do ar. Temperatura da superfície, Tefé, Amazonas.

\begin{abstract}
The aim of the research was to analyze the thermal field and the heat islands in a city of equatorial climate in the Brazilian Amazon. The spatial clipping was the city of Tefé, located in the region of the Middle Solimões in the interior of the state of Amazonas. For this, mobile transects were performed on representative days of the month of October, which is inserted in the less rainy seasonal period called the Amazonian summer, to collect air temperature data in 37 points of the city. The data were tabulated and interpolated by the IDW method in the QGIS software. The surface temperature chart and the NDVI were also generated for analysis of the thermal structure and soil occupation. The thermal differences between the points varied up to $4.6^{\circ} \mathrm{C}$, and in the central part of the city of the oldest occupation, construction density and sparse urban afforestation, the island of heat was of great magnitude. Surface temperatures varied from $25^{\circ} \mathrm{C}$ to $30^{\circ} \mathrm{C}$ and also indicated the concentration of heating in the central part, derived from the wide coverage of constructive materials inappropriate for the equatorial climate. In addition, it was verified that the high density of arboreal vegetation was associated to the configuration of the island of freshness. It is concluded that the urban climate studies should be articulated to the planning and (re) production of the urban space, since even located in the middle of the deep Amazon the social production of the urban climate in an unequal way can potentiate problems related to thermal discomfort and the health of part of the population.
\end{abstract}

Keywords: Urban Climate. Air Temperature. Surface Temperature. Tefé. Amazonas.

\section{INTRODUÇÃO}


Os estudos dos climas urbanos nas regiões tropicais têm sua gênese na climatologia geográfica desde a década de 1970, porém, primeiramente com enfoque maior nas regiões metropolitanas devido às alterações significativas nos parâmetros meteorológicos e posteriormente, foram estudadas as cidades de porte médio e pequeno.

Foi a partir da proposta teórica-metodológica apresentada por Monteiro (1976) sobre o estudo do sistema clima urbano na ciência geográfica, que se ampliou as pesquisas sobre essa temática, norteando uma abordagem que incorpora a dimensão da natureza e da sociedade, nos fluxos de entrada e saída de matéria e energia envolvendo a superfície e a atmosfera.

Os progressos qualitativos na compreensão da atmosfera urbana bem como quantitativos ocorreram com as aplicações da proposta do sistema clima urbano em estudos de caso em várias partes do país, além da utilização de instrumentação técnica, sensoriamento remoto e maior disponibilidade de dados meteorológicos nos últimos trinta anos. (AMORIM, 2005, 2013; AMORIM et al 2009, FIALHO, 2010, 2012; MENDONÇA, 2015).

Dentre os subsistemas propostos: o termodinâmico, o físico-químico e o hidrometeórico, o primeiro com predomínio analítico do campo térmico, concentra a maior atenção das pesquisas na climatologia geográfica brasileira, porém, a espacialização das teses e dissertações produzidas na Geografia de 1990 a 2010 demonstrou forte concentração dos estudos principalmente nas regiões Sul e Sudeste, com menor proporção na região Norte do país. (MENDONÇA, 2015)

Com relação aos diferentes tipos climáticos do Brasil os estudos de cidades localizadas em clima equatorial (domínio climático quente e úmido) com características de expressiva homogeneidade térmica, baixa amplitude térmica mensal, amplo volume pluviométrico anual em algumas partes e subdivisões relacionadas à variabilidade da umidade do ar, são escassos. (MENDONÇA e DANNIOLIVEIRA, 2007). 
Refletindo sobre a análise do subsistema termodinâmico essa carência suprime a compreensão de aspectos importantes sobre o conforto térmico, os efeitos do desconforto na fisiologia humana, o fator de visão do céu (sky view fator) e as ilhas de calor e frescor nas áreas urbanas de clima equatorial.

No estado do Amazonas, por exemplo, os estudos realizados sobre o campo térmico restringem-se a capital Manaus (AGUIAR, 1995; SILVA e AGUIAR, 2012; VIANA et al., 2012; CORREA et al., 2016) e as cidades interioranas carecem de pesquisas que compreendam as alterações do clima e da qualidade ambiental urbana e que possibilitem instrumentos de gestão e medidas de planejamento urbano que incorporem a perspectiva climática no bem-estar e qualidade de vida da população.

Neste contexto, o objetivo deste trabalho foi analisar o campo térmico e as ilhas de calor em uma cidade de clima equatorial na Amazônica brasileira. O recorte espacial do estudo foi à cidade de Tefé, localizada na região do Médio Solimões no interior do estado do Amazonas.

\section{CARACTERIZAÇÃO DA ÁREA DE ESTUDO}

O Amazonas é o maior estado da Amazônia brasileira e grande parte dos municípios, incluindo Tefé, inserem-se na denominada "Amazônia profunda", devido a pouca magnitude da transformação da paisagem comparada a outras partes do domínio Amazônico, caracterizada conforme Viana (2008), por uma baixa taxa de desmatamento, presença de populações indígenas e tradicionais, alta proporção de áreas protegidas e dificuldade de acesso por estradas.

Tefé está localizado a $520 \mathrm{~km}$ em linha reta de Manaus, capital do Amazonas, de acordo com a figura 1, possui 61.456 habitantes e desde a década de 1980 a população urbana é superior a rural, conforme o Instituto Brasileiro de Geografia e Estatística (IBGE, 2010).

Schor e Oliveira (2011) classificaram a rede urbana do estado do Amazonas e definiram Tefé como cidade média com responsabilidade territorial, considerada um importante "nó" da rede urbana da calha do Rio Solimões. 


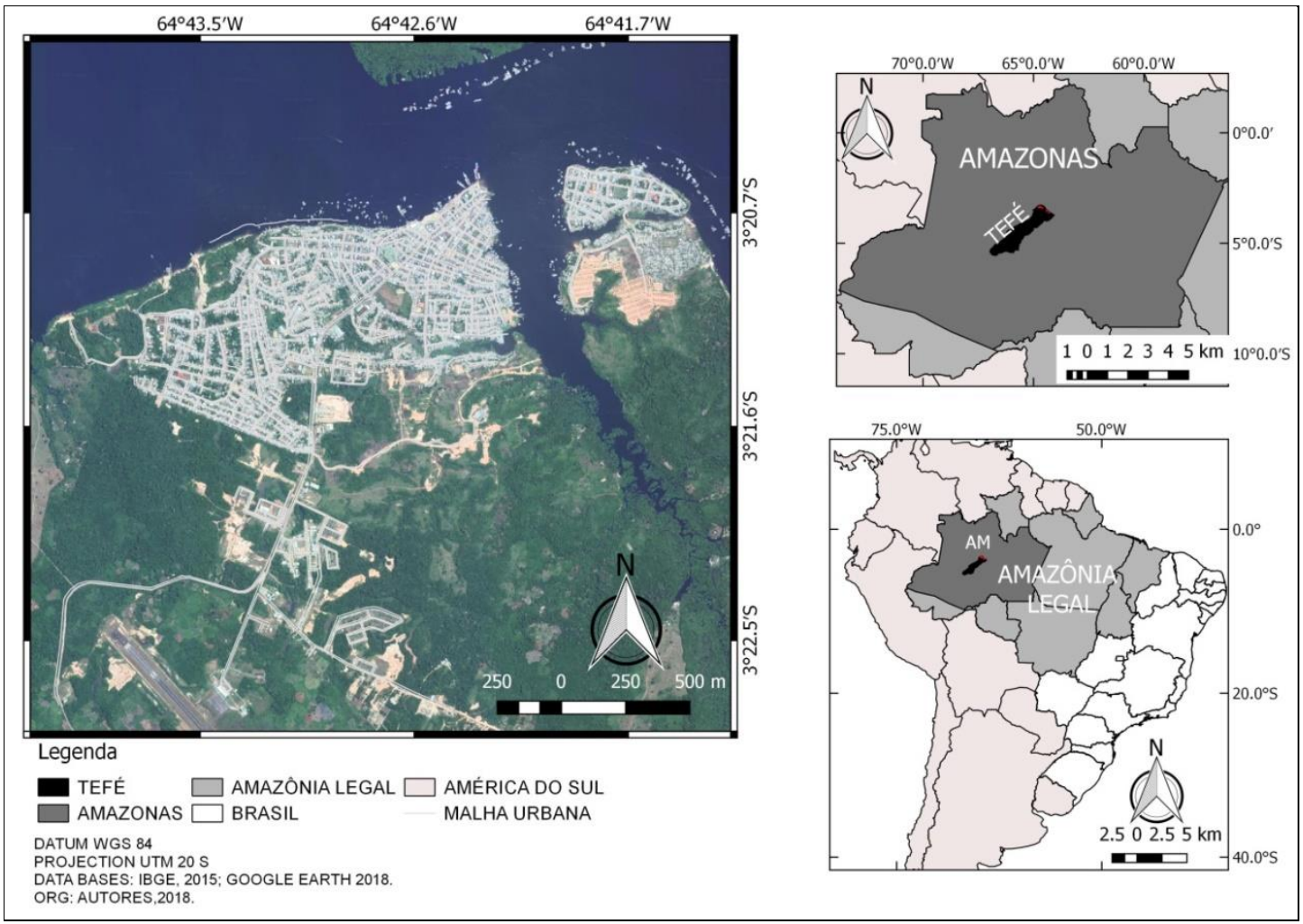

Figura 1. Localização da área de estudo. Org.: Autores, 2018.

O clima da região Amazônica apresenta pouca amplitude térmica sazonal, as chuvas são controladas por sistemas dinâmicos de grande escala como a Zona de Convergência Intertropical (ZCIT), a circulação de Hadley e Walker e pela associação atmosfera-oceano por meio das anomalias da temperatura dos oceanos (TSM) do Atlântico e Pacífico que definem a variabilidade e afetam a atuação da ZCIT e da circulação de Walker.

Predomina na região a atuação de sistemas atmosféricos como a Zona de Convergência Intertropical (ZCIT) e Alta da Bolívia (AB). A Zona de Convergência do Atlântico Sul (ZCAS) também atua do período de novembro a abril e contribui para o aumento dos totais de chuvas na região (MOLION, 1987; MARENGO e NOBRE, 2009).

Os sistemas frontais entre os meses de junho/outubro em conjunto com a organização do movimento convectivo, contribuem para chuvas e diminuição da temperatura na região, (FISCH et al., 1998; KOUSKY e KAGANO, 1981). Além disso, a frequência de linhas de instabilidade durante a época 
denominada de seca na Amazônia Central é também responsável pelas chuvas na região, (MOLION, 1987, FISCH et al., 1998).

As normais climatológicas provisórias de Tefé, no gráfico 1, demonstraram que a temperatura máxima anual foi de $32,4^{\circ} \mathrm{C}$ a média anual de $26,8^{\circ} \mathrm{C}$ e a mínima de $22,5^{\circ} \mathrm{C}$, com baixa amplitude térmica sazonal que variou de $0,8^{\circ} \mathrm{C}$ para a temperatura mínima e $1,7^{\circ} \mathrm{C}$ para a temperatura máxima ao longo dos meses do ano. $O$ mês que apresentou os valores mais elevados de temperatura máxima foi outubro.

A precipitação média anual do período $1981-2010$ foi de $2445,7 \mathrm{~mm}$. Caracteriza-se no município a sazonalidade distinta pelas chuvas, pois, os maiores volumes mensais de ocorreram nos meses de dezembro a maio, período chuvoso ("inverno amazônico") e de junho a outubro período mais seco (“verão amazônico), sendo o mês de novembro considerado de transição.

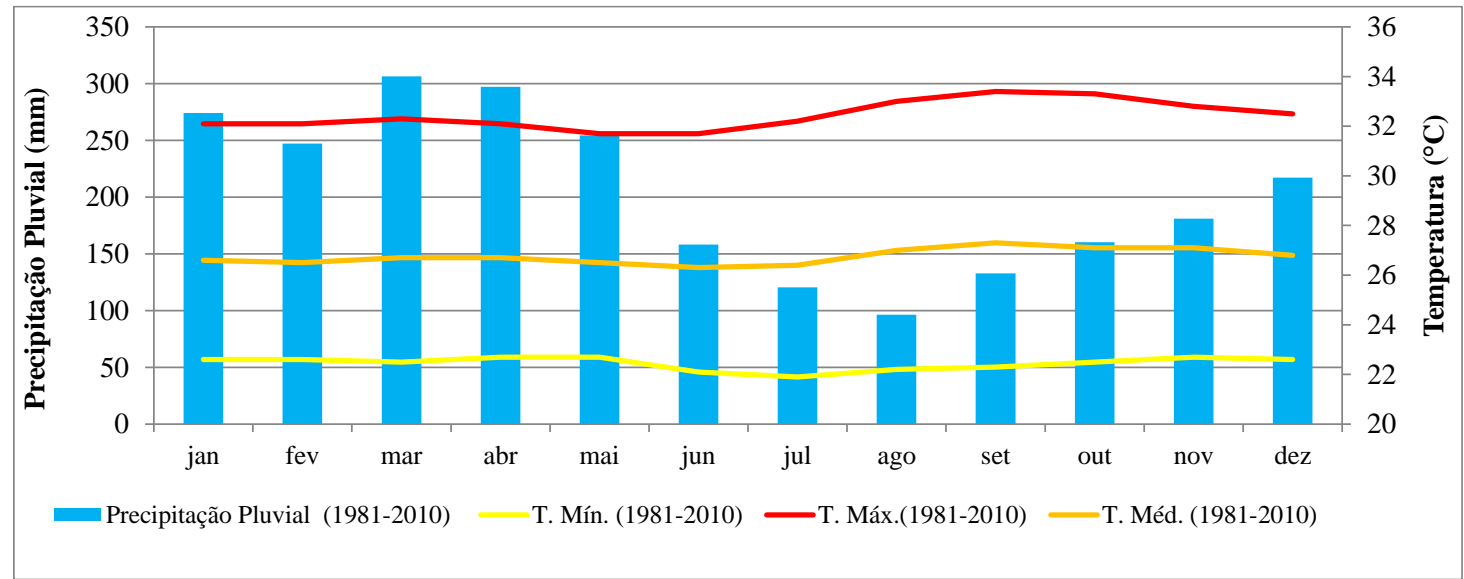

Gráfico 1. Normais climatológicas provisórias de Tefé-AM do período de 1981-2010. Fonte: INMET, 2018. Org.: Autores, 2018.

\section{PROCEDIMENTOS METODOLÓGICOS}

O referencial teórico e metodológico baseou-se na análise do sistema clima urbano (Monteiro, 1976) com enfoque no subsistema termodinâmico.

Foram realizadas coleta de dados de temperatura do ar e umidade relativa do ar com aparelho termohigrômetro digital da marca Incoterm, por meio da metodologia do transecto móvel aplicadas em diversas pesquisas (PITTON, 1997; AMORIM, 2005; FIALHO, 2009; FIALHO et al, 2016; 
ARAÚJO et al., 2010; UGEDA JÚNIOR, 2012; ORTIZ PORANGABA, 2015) que colaboram com a compreensão dos mecanismos que configuram as ilhas de calor (OKE, 1987). A mensuração foi realizada com o acoplamento do termohigrômetro a uma vara de bambu protegida na parte superior por material isolante (isopor) na cor branca, onde o sensor localizou-se a 1,5 m do solo. A velocidade do automóvel utilizado nos transectos não ultrapassou $35 \mathrm{~km} / \mathrm{hora}$.

Os transectos foram realizados nos dias 11, 12, 19 e 20 do mês de outubro devido à sazonalidade climática referente ao período menos chuvoso, em que as condições de maior estabilidade atmosférica e de nebulosidade permitiram a verificação das diferenças térmicas e intensidades das ilhas de calor.

Os dados foram coletados no horário das 21:00h no percurso estabelecido na área urbana composto por 37 pontos, definidos por apresentarem diferentes caraterísticas de uso e ocupação do solo. 0 transecto foi realizado dentro do tempo médio de 40 minutos entre o início e término da mensuração.

Os dados da temperatura do ar foram tratados no software Excel, após o tratamento estatístico dos dados, realizou-se a interpolação dos dados utilizando-se o método de Ponderação do Inverso das Distâncias (Inverse Distance Weighting) no software QGIS, esse método de interpolação estima medidas desconhecidas de um campo contínuo para locais onde não há medidas disponíveis (LONGLEY, et al. 2013).

Para a análise dos dados também foi calculada as diferenças da temperatura de cada ponto subtraindoas pela menor temperatura registrada no transecto conforme Fernández García (1996). As diferenças térmicas foram utilizadas para compreensão das intensidades das ilhas de calor.

O percurso foi definido considerando dois trajetos $\mathrm{A}$ e $\mathrm{B}, \mathrm{C}$ e $\mathrm{D}$, apresentado na figura 2 , que mostram características distintas de uso e ocupação do solo integrando as características ambientais e urbanas da cidade. 


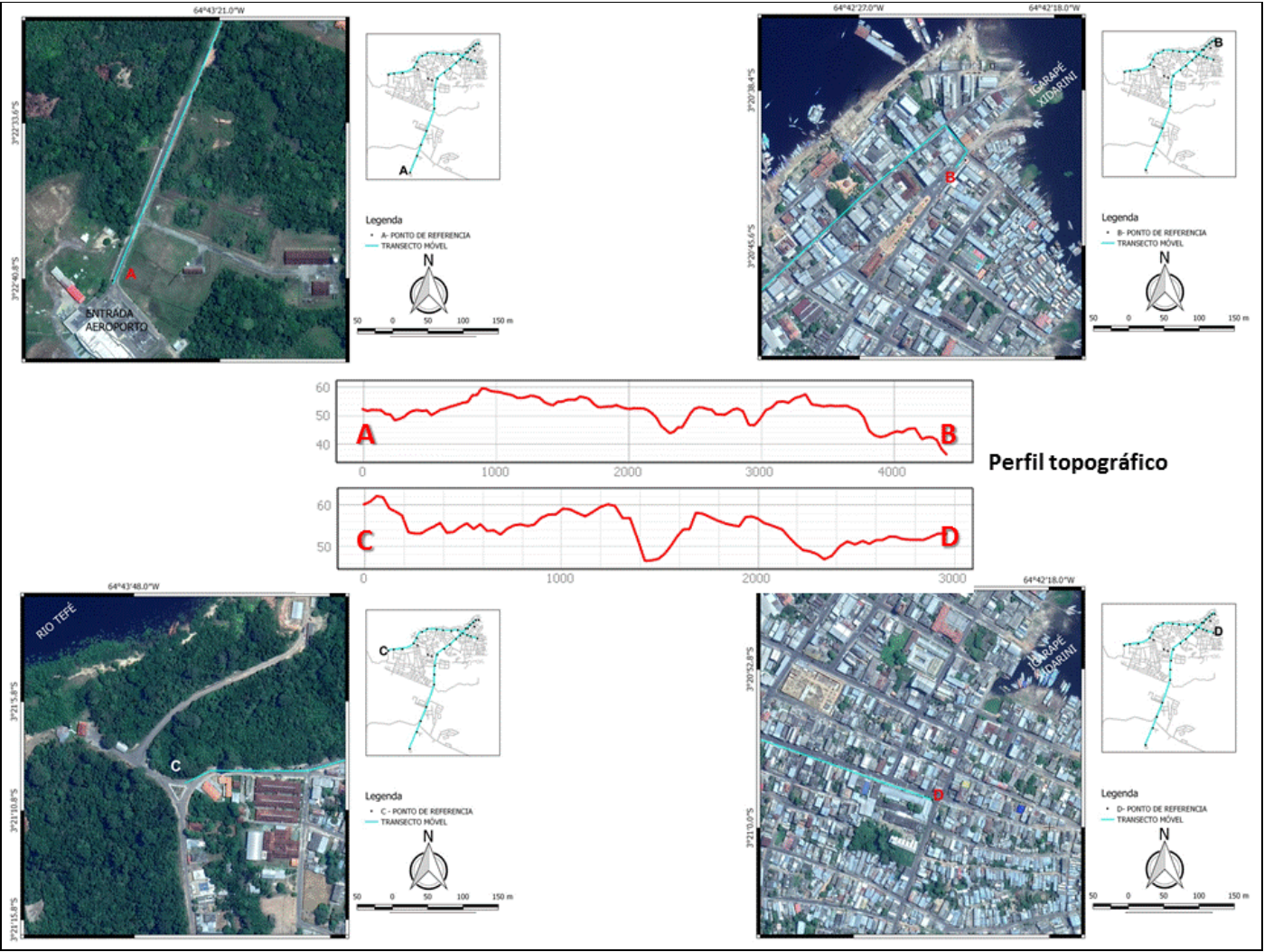

Figura 2. Localização das áreas de realização do transecto e perfil topográfico. Org: Autores, 2018.

Área A: que apresenta o entorno com ampla vegetação arbórea, construções esparsas devido a presença de vilas militares, pouca impermeabilização do solo e fluxo de veículos e pessoas. Englobando a área do aeroporto limítrofe da malha urbana e próxima à floresta primária e propriedades agrícolas.

Área B: Composta por ampla densidade de construções, com grande quantidade de edifícios de 2 a 3 pavimentos, uso do solo com predomínio comercial e de serviços no piso inferior e residencial nos pisos superiores. O fluxo de veículos e pessoas é intenso durante o período diurno e moderado a noite, a vegetação arbórea é esparsa e a próxima com o rio Tefé.

Área C: Área com moderada densidade de construções, ampla presença de edifícios de 1 pavimento, com uso residencial e de serviços, localizada a margem do Rio Tefé, com vegetação arbórea moderada, fluxo de veículos e pessoas moderado no período diurno e baixo no período noturno.

Área D: Área densamente construída, com média quantidade de edifício de 2 e 3 pavimentos de uso comercial e residencial e também constituído por moradias populares, fluxo de veículos e pessoas 
intenso durante o dia e moderado a noite, vegetação arbórea esparsa, uso do solo comercial e de serviços.

Os sistemas atmosféricos atuantes nos dias das mensurações foram identificados por meio das imagens de satélites GOES 16 e do boletim técnico do Centro de Previsão do Tempo e Estudos Climáticos do Instituto Nacional de Meteorologia (CPTEC/INPE).

Para melhor compreensão da estrutura térmica e índice de vegetação na área urbana de Tefé também foram produzidas cartas do índice de vegetação da diferença normalizada (NDVI) e da temperatura da superfície.

O processamento de produtos de sensoriamento remoto, utilizou os procedimentos propostos pelo USGS - United State Geological Survey (2018), para conversão dos Níveis digitais da Imagens Landsat 8 OLI (Operational Land Imager) e TIRS (Thermal Infrared Sensor) em produtos como temperatura da superfície e índices de vegetação (NDVI - Normalized Difference Vegetation Index).

Os dados do Landsat 8, foram redimensionados para a refletância no caso do NDVI e radiância do Topo da atmosfera (TOA- Top Of Atmosphere) e posteriormente Temperatura de Brilho em graus Celsius (BT - Brightness Temperature) para o produto de Temperatura da superfície.

Foram utilizados coeficientes de redimensionamento radiométrico fornecidos nos metadados da imagem Landsat 8 Level-1 OLI/TIRS, Órbita Ponto 001/062 de 15 de junho de 2015, que compreende a cidade de Tefé e suas adjacências.

Os redimensionamentos de valores de pixels (ND - Nível Digital) em reflectância e radiância foram processados utilizando a calculadora Raster do Software Quantum GIS, resultando nos respectivos produtos finais: NDVI e Temperatura da superfície. 
Para elaboração do NDVI, utilizou-se as bandas 4 e 5, respectivamente Vermelho (R) e Infravermelho próximo (NIR) do Landsat 8 OLI, o NDVI é um parâmetro para se estabelecer os níveis de reflectância da vegetação sadia, permitindo a análise de áreas de vegetação densa, como as áreas de floresta e dispersa como áreas de pastagem, desmatamento, agricultura e expansão urbana.

Objetivando a elaboração de NDVI, foram utilizados dos metadados da imagem em que se aplicou a Equação 1, em que foi realizado a correção atmosférica de cada banda, e redimensionados os níveis digitais (ND) para reflectância do TOA (Topo da atmosfera) das bandas 4 e 5, enfatiza-se que 0 mesmo processo foi realizado para as bandas 4 e 5, que apresentam os mesmos parâmetros de metadados para o Fator de redimensionamento Multiplicativo e Fator de redimensionamento Aditivo (USGS, 2018).

Equação 1: $\boldsymbol{\rho}_{\lambda}=\frac{M_{p} * Q_{c a l}+A_{p}}{\sin \left(\theta_{s e}\right)}$

Onde:

$\boldsymbol{\rho}_{\lambda}=$ Reflectância TOA, com correção para o ângulo solar.

$\boldsymbol{M}_{\boldsymbol{p}}=$ Fator de redimensionamento multiplicativo específico da banda dos metadados

(REFLECTANCE_MULT_BAND_4 $=2.0000 \mathrm{E}-05)$.

$\boldsymbol{Q}_{\boldsymbol{c a l}}=$ Valores de pixel do produto padrão (DN) quantizados e calibrados, ou seja, a banda que será processada (LC08_L1TP_001062_20150730_20180129_01_T1_B4.TIF)

$\boldsymbol{A}_{\boldsymbol{p}}=$ Fator de redimensionamento aditivo específico da faixa dos metadados (REFLECTANCE_ADD_BAND_4 $=-0.100000)$

$\sin =$ Função Seno

$\left(\boldsymbol{\theta}_{\boldsymbol{s e}}\right)=$ Ângulo de elevação do sol local. O ângulo de elevação do sol do centro da cena em graus é fornecido nos metadados (SUN_ELEVATION $=54.31355777)$.

Após a correção atmosférica e redimensionados dos níveis digitais para reflectância do topo da atmosfera das bandas $4(\mathrm{R})$ e $5(\mathrm{NIR})$, foi realizado o processamento das bandas implementando a Equação 2, em calculadora Raster do Software QGIS, para obtenção dos NDVI.

Equação 2: NDVI $=\frac{(N I R-R)}{(N I R+R)}$

Onde: 


\section{NDVI = Normalized Difference Vegetation Index}

NIR = Banda 5 do Landsat 8 OLI, Infravermelho Próximo, com correção atmosférica e redimensionados para reflectância, resultado do processamento da Equação 1.

$\mathbf{R}=$ Banda 4 do Landsat 8 OLI, Vermelho, com correção atmosférica e redimensionados para reflectância, resultado do processamento da Equação 1.

Após a conversão de ND em reflectância, e aplicação da Equação 2, resultou um produto raster do NDVI, que apresentou valores que variam de -1, a 1, observando-se que os valores próximos de -1, a vegetação é mais dispersa ou inexistente, os valores próximos a 1 a vegetação é mais densa e homogênea.

Para elaboração do produto da temperatura da superfície, realizou-se o processamento da Banda 10, utilizando os metadados da imagem, em que se aplicou a Equação 3, para redimensionar os níveis digitais (ND) para radiância do TOA (Topo da atmosfera):

Equação 3: $\boldsymbol{L}_{\lambda}=\boldsymbol{M}_{\boldsymbol{l}} * \boldsymbol{Q}_{\text {cal }}+\boldsymbol{A}_{\boldsymbol{l}}$

Onde:

$\boldsymbol{L}_{\lambda}=$ Radiação espectral de TOA (Watts / $\left.\left(\mathrm{M}^{2 *} \operatorname{srad}^{*} \mu \mathrm{m}\right)\right)$

$\boldsymbol{M}_{\boldsymbol{l}}=$ Fator de redimensionamento multiplicativo específico da banda dos metadados (RADIANCE_MULT_BAND_10 $=3.3420 \mathrm{E}-04)$.

$\boldsymbol{Q}_{\boldsymbol{c a l}}=$ Valores de pixel do produto padrão (DN) quantizados e calibrados, ou seja, a banda que será processada (LC08_L1TP_001062_20150730_20180129_01_T1_B10.TIF)

$\boldsymbol{A}_{\boldsymbol{l}}=$ Fator de redimensionamento aditivo específico da faixa dos metadados $($ RADIANCE_ADD_BAND_10 $=0.10000)$

Posteriormente, foram obtidas as constantes térmicas necessárias para converter dados de banda térmica em TOA para Temperatura de brilho em graus Celsius (BT - Brightness Temperature), esse processamento foi realizado aplicando-se a Equação 4.

Equação 4: $T=\frac{K_{2}}{\ln \left(\frac{K_{1}}{L_{\lambda}+1}\right)}-273.15$

Onde:

$\mathbf{T}=$ Temperatura da superfície em graus Célsius

$\boldsymbol{K}_{\mathbf{2}}=$ Constante de conversão térmica específica da banda dos metadados

(K2_CONSTANT_BAND_10 = 1321.0789) 
$\boldsymbol{K}_{\mathbf{1}}=$ Constante de conversão térmica específica da banda dos metadados

$($ K1_CONSTANT_BAND_10 $=774.8853)$

$\ln =$ Função Logaritmo

$\boldsymbol{L}_{\boldsymbol{\lambda}}=$ Radiação espectral de TOA (Produto da Equação 3)

- 273.15 = Valor subtraído para conversão de graus Kelvin em graus Celsius

Dessa maneira os produtos gerados foram discutidos em conjunto para compreensão do campo térmico da cidade de Tefé.

\section{O CAMPO TÉRMICO EM TEFÉ-AM: UMA ANÁLISE EPISÓDICA}

Com relação às características geoambientais, a cidade de Tefé apresenta altitudes que variam entre 30 a 60 metros aproximadamente, a malha urbana possui releve com características plano e suavemente ondulado. 0 centro comercial da cidade, de ocupação mais antiga localiza-se na área de menor altitude próxima do rio Tefé, correspondendo às áreas B e D.

Nos dias 11 e 12 de outubro a análise sinótica no nível de 500hpa demonstrou uma circulação anticiclônica sobre a região Norte do Brasil, a Zona de Convergência Intertropical (ZCIT) atuou em torno de $08^{\circ} \mathrm{N} / 10^{\circ} \mathrm{N}$ sobre os Oceanos Pacífico e Atlântico, porém, a termodinâmica favoreceu a formação de áreas de instabilidade e aumento da nebulosidade em alguns períodos. No dia 11, Tefé esteve parcialmente nublada no período noturno, porém, no dia 12 a nebulosidade foi baixa.

No dia 11 de outubro, no horário das 21h., a temperatura do ar mensurada nos pontos oscilou de $25,4^{\circ} \mathrm{C}$ a $27,9^{\circ} \mathrm{C}$, de acordo com a figura 3 . Os pontos que apresentaram maior temperatura do ar foram localizados na área central da cidade, em que predomina o uso do solo por comércio e serviços, impermeabilização hegemônica e com pouca vegetação arbórea.

Os pontos com menores temperaturas ocorreram na estrada do aeroporto, área com ampla vegetação arbórea, na parte limítrofe urbana e próxima a floresta primária.

A diferença térmica demonstrou variação máxima de $2,5^{\circ} \mathrm{C}$ entre o trajeto $\mathrm{A}$ e o $\mathrm{B}$ e $\mathrm{D}$. 
No dia 12 de outubro, às $21 \mathrm{~h}$. a temperatura do ar variou de $25,6^{\circ} \mathrm{C}$ a $30^{\circ} \mathrm{C}$, conforme a figura 4 .

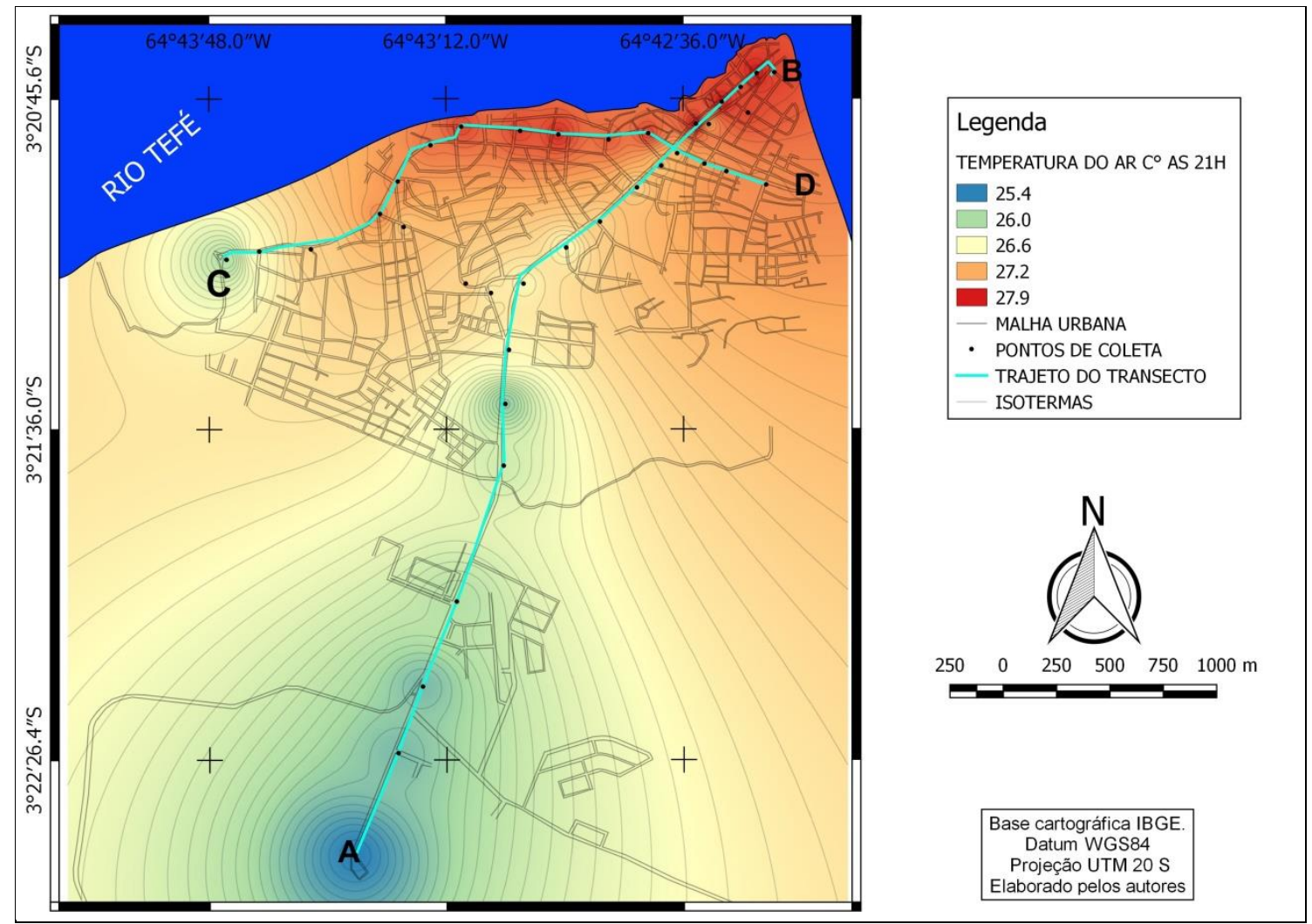

Figura 3. Temperatura do ar em Tefé no dia 11/10/2016 - 21h.

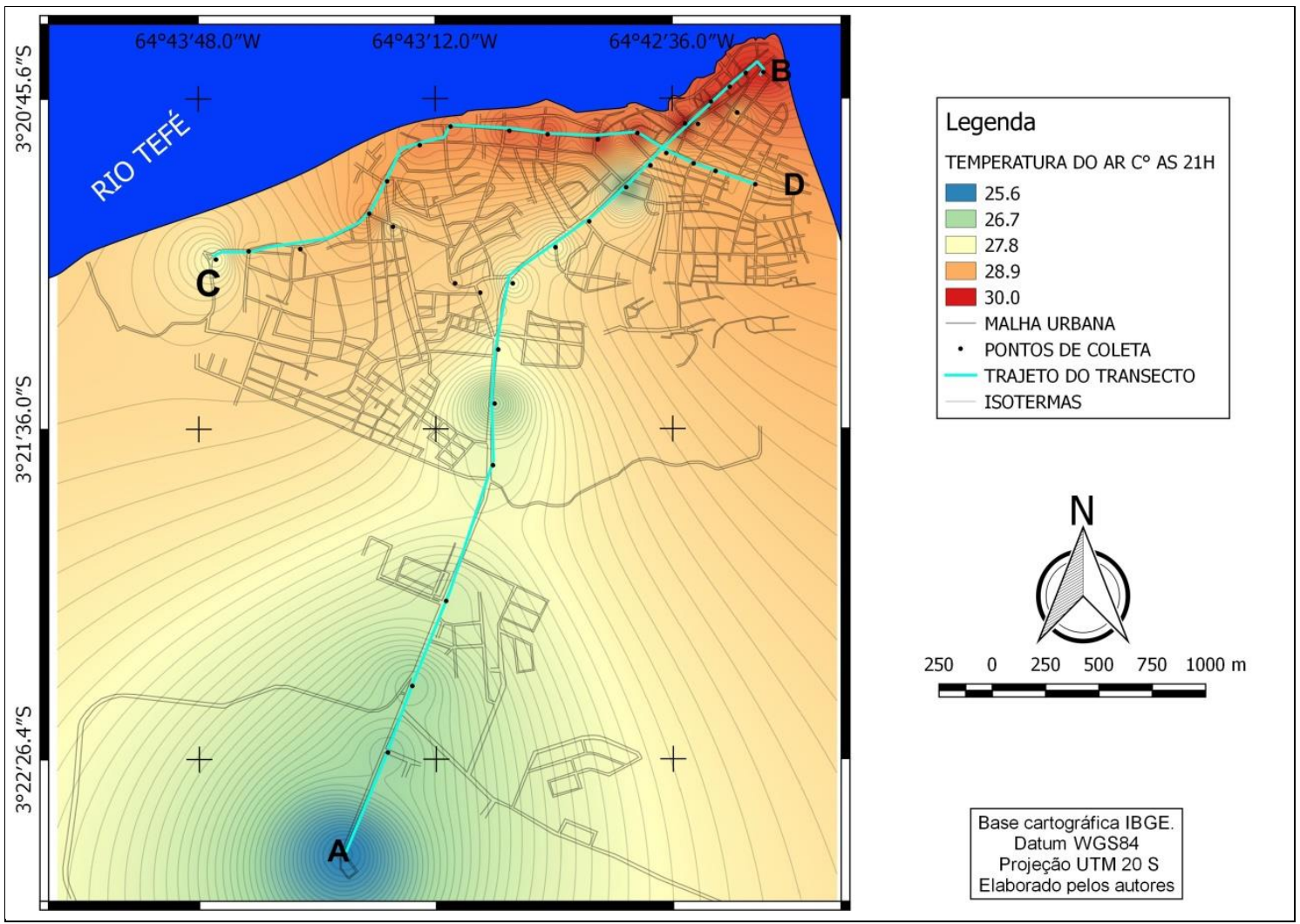

Figura 4. Temperatura do ar em Tefé no dia 12/10/2016 - 21h. 
A temperatura de $25,6^{\circ} \mathrm{C}$ foi mensurada no aeroporto (Área A) e a de $30^{\circ} \mathrm{C}$ na parte central (Área B), que possui maior impermeabilização, fluxo de veículos e pessoas.

A diferença de temperatura do ar entre os pontos, apresentou o valor máximo de $4,4{ }^{\circ} \mathrm{C}$ do percurso, na Área A observou-se a menor temperatura com relação à B e D, demonstrando segundo a figura 5 , a configuração da ilha de calor de forte intensidade, em áreas próximas do centro comercial da cidade de Tefé, representando que as áreas com vegetação arbórea esparsa ou inexistente e áreas densamente construída e mais aquecidas.

As diferenças térmicas mais elevadas ocorreram nos pontos da parte central densamente construída, com presença ampla de edificações de 2 a 3 pavimentos e escassez de vegetação arbórea. Nessa área é predominante o uso do solo comercial e de serviços, também possui intenso fluxo de veículos do tipo motocicleta e a ventilação natural nessa área é canalizada entre os prédios. Ocorre também maior presença de edifícios com telhas de fibrocimento e alumínio e ampla utilização de climatizadores artificiais.

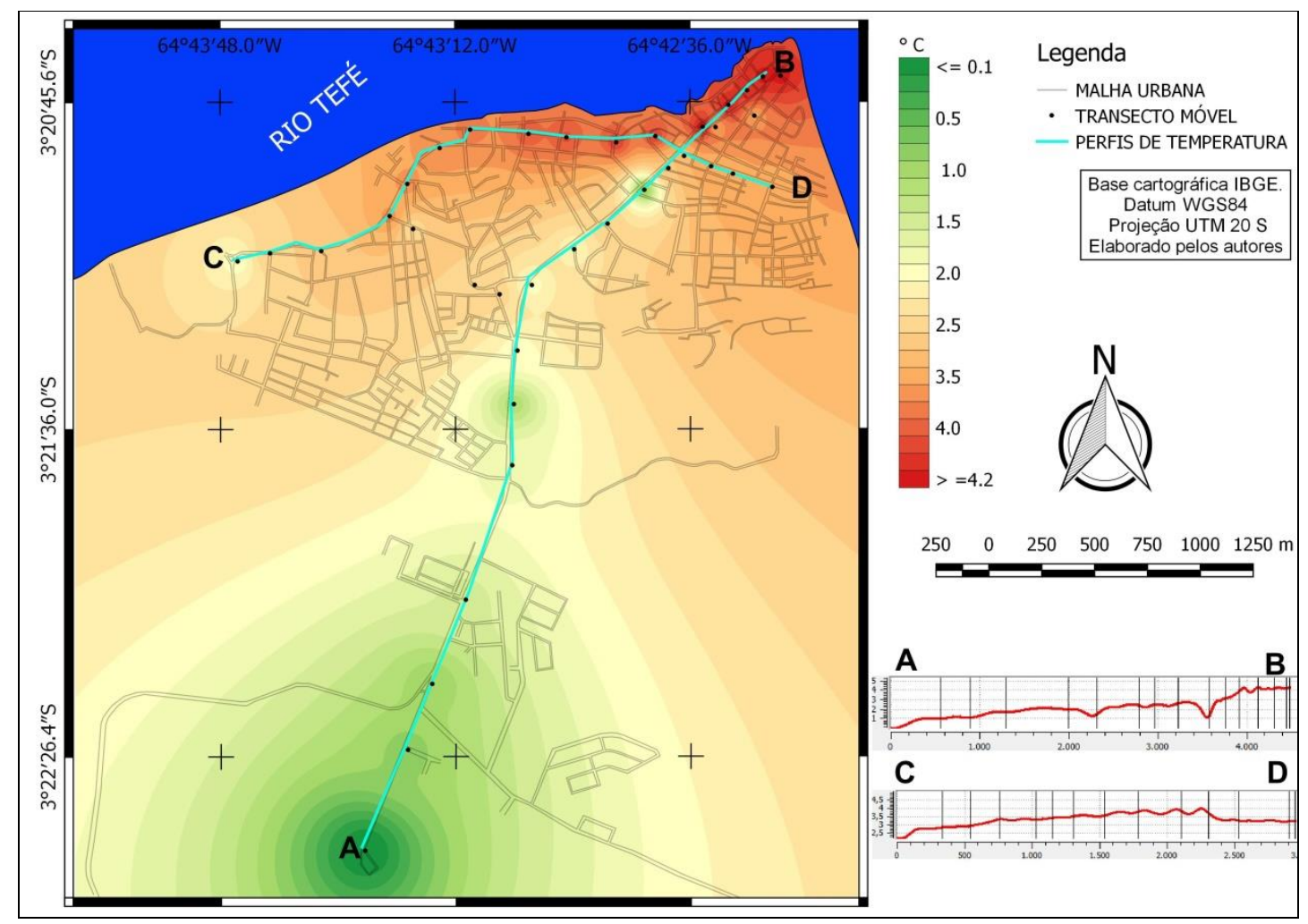

Figura 5. Diferenças da temperatura do ar no dia 12/10/2016 em Tefé - 21h. 
A análise sinótica efetuada no nível 500hpa mostra um padrão de circulação anticiclônica sobre parte da Região Norte entre os dias 19 e 20 de outubro. No dia 19 de outubro a presença da Zona de Convergência Intertropical (ZCIT) atuou em torno de $07^{\circ} \mathrm{N} / 10^{\circ} \mathrm{N}$ sobre os oceanos Pacífico e entre $05^{\circ} \mathrm{S} / 09^{\circ} \mathrm{W}$ no Atlântico, a termodinâmica da região Norte derivada do calor e umidade propiciaram a ocorrência de aglomerado convectivo que ocasionou fraca precipitação pluvial de $2,7 \mathrm{~mm}$ no município de Tefé, o céu apresentou-se parcialmente nublado no período noturno, porém, com calmaria dos ventos.

No período noturno das $21 \mathrm{~h}$. às temperaturas tiveram variação de $26,5^{\circ} \mathrm{C}$ a $31,1^{\circ} \mathrm{C}$, sendo que os pontos na parte central da cidade (Áreas B e D) apresentaram valores acima de $30^{\circ} \mathrm{C}$. A menor temperatura foi observada no ponto do aeroporto (Área A). A figura 6 representa o armazenamento de calor na parte central, provavelmente associado ao uso e ocupação do solo, extensa impermeabilização, trânsito intenso de veículos e a escassez de vegetação arbórea.

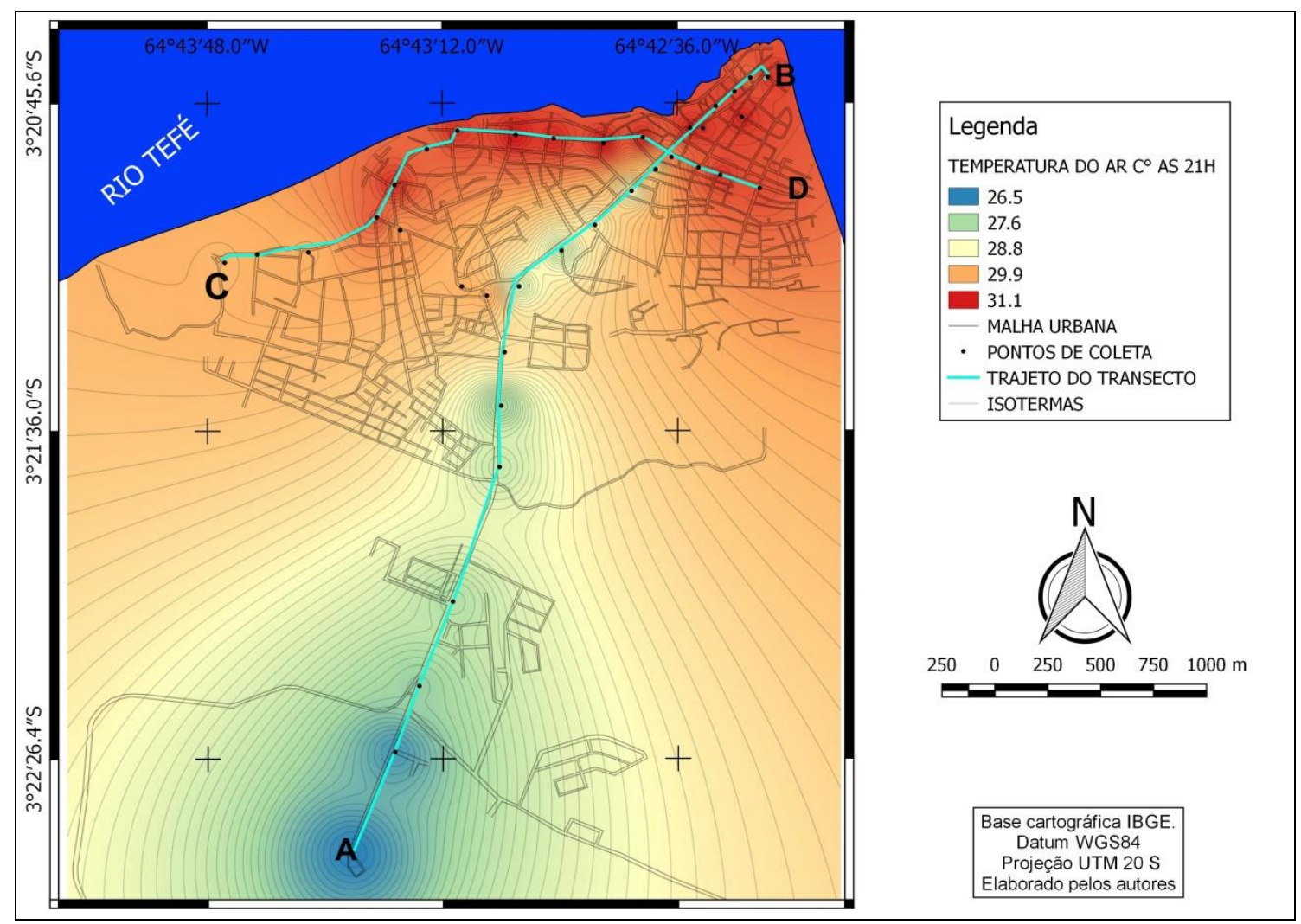

Figura 6. Temperatura do ar em Tefé no dia 19/10/2016 - 21h. 
A maior diferença térmica foi de $4,6^{\circ} \mathrm{C}$ entre os pontos, seguindo a Área A de menor temperatura, caracterizando-se como da ilha de frescor com relação às Áreas B e D. As áreas características das ilhas de calor de forte intensidade nas Áreas B e D, fazem parte do núcleo mais impermeabilizado da cidade, devido o uso por atividades comerciais e serviços. (Figura 7)

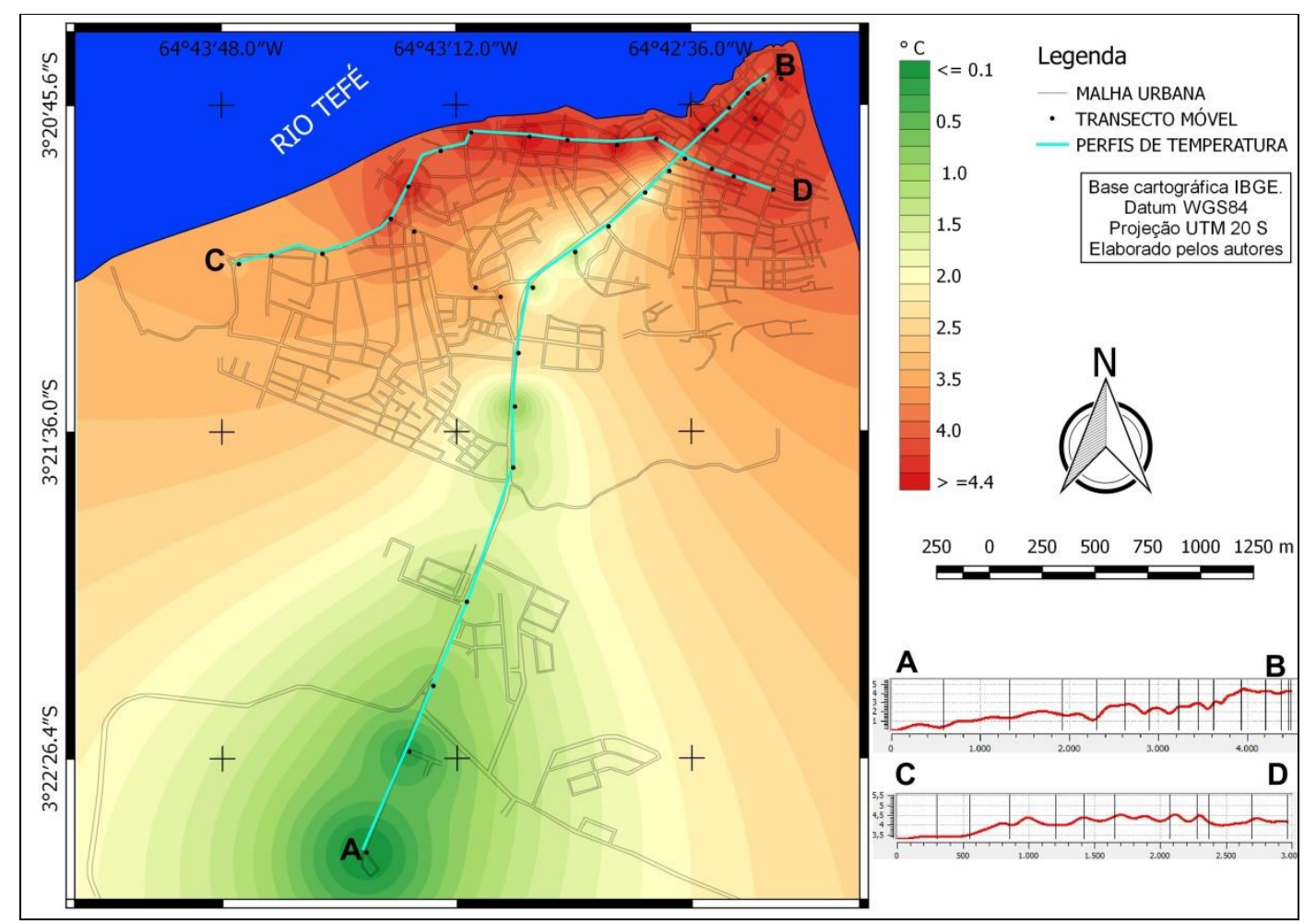

Figura 7. Diferenças da temperatura do ar no dia 19/10/2016 em Tefé $-21 \mathrm{~h}$.

Na análise sinótica do dia 20 de outubro verificou-se o escoamento associado aos Jatos de Baixos Níveis (JBN) que transportou o ar relativamente mais úmido e quente do oeste da região Amazônica para o Sul do Brasil.

O sistema de grande escala da Zona de Convergência Intertropical (ZCIT) atuou em torno de $07^{\circ} \mathrm{N} / 10^{\circ} \mathrm{N}$ sobre os oceanos Pacífico e entre $05^{\circ} \mathrm{S} / 08^{\circ} \mathrm{W}$ no Atlântico e favoreceu aliada a termodinâmica regional a formação de áreas de instabilidade. Em Tefé, a formação de nebulosidade ocasionou a precipitação pluvial registrada de 8,2mm no dia 21 de outubro. 
No horário das 21 h. do dia 20 de outubro, observou-se a variação da temperatura do ar entre $25,3{ }^{\circ} \mathrm{C}$ e $27,5^{\circ} \mathrm{C}$, apresentando o perfil característico de elevadas temperaturas na parte central e diminuição na estrada do aeroporto e entorno (Figura 8).

As diferenças de temperatura foram de até $2,2^{\circ} \mathrm{C}$, demonstrando intensidades moderadas nas áreas $\mathrm{B}$ e D e menores na área A. Com relação aos dias anteriores, as diferenças térmicas em decorrência do aumento da nebulosidade e da velocidade do vento foram menores no ambiente intraurbano.

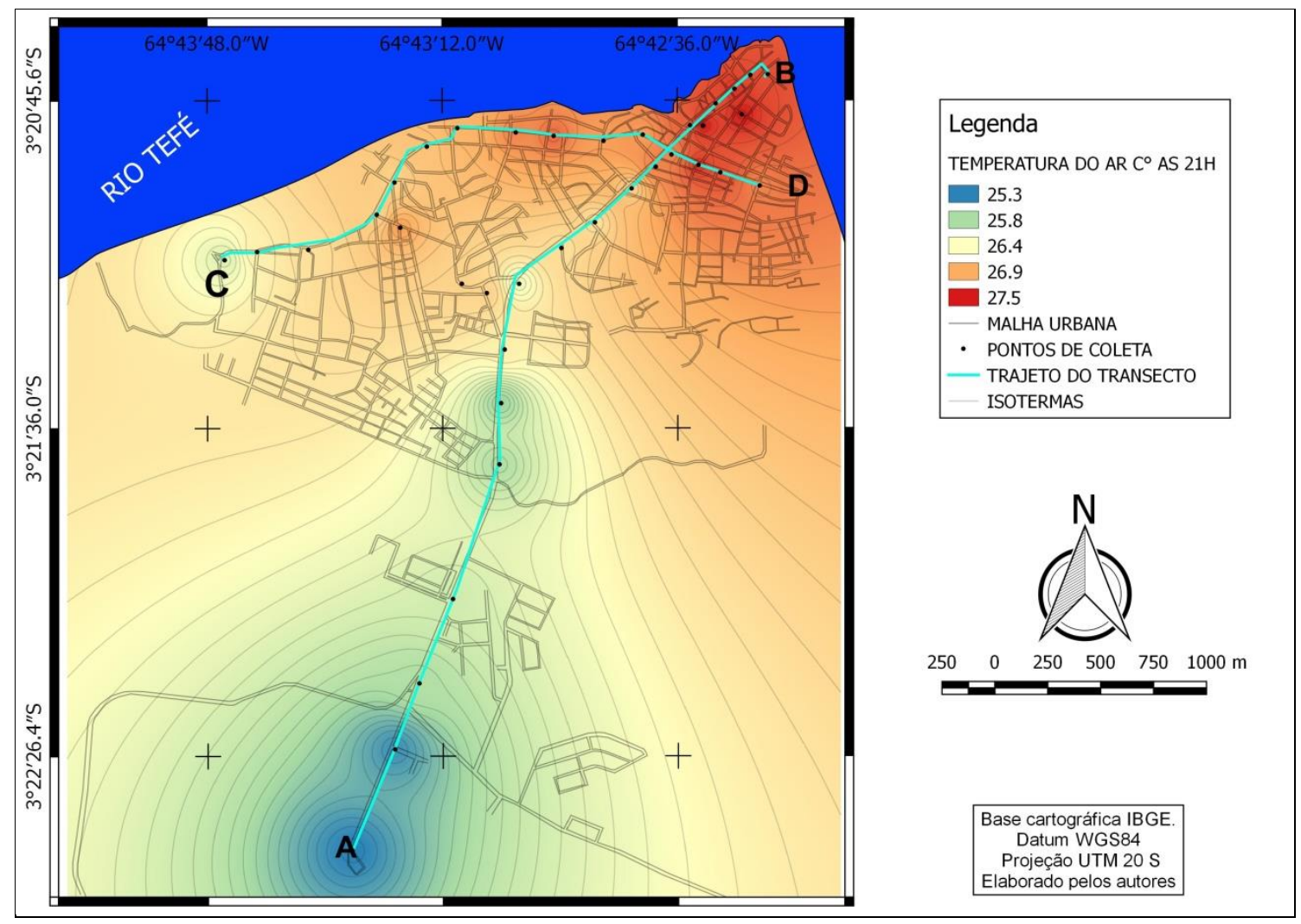

Figura 8. Temperatura do ar em Tefé no dia 20/10/2016 - 21h

\section{A TEMPERATURA SUPERFICIAL URBANA EM TEFÉ}

A disponibilidade das imagens do Satélite Landsat 8 TIRS, para elaboração da temperatura superficial de Tefé foi reduzida devido a ampla presença de nuvens durante o horário da passagem do satélite. Por isso, foi elaborada a carta termal utilizando a imagem do dia 15 de junho 2015, característico do período menos chuvoso e que demonstrou as diferenças nas densidades de contruções, arborização, corpos d'água e da ocupação do solo. 
As temperaturas da superfície variaram de $25^{\circ} \mathrm{C}$ a $30^{\circ} \mathrm{C}$ na cidade de Tefé, segundo a figura 9 . Os bairros das áreas $\mathrm{B}$ e $\mathrm{D}$, parte central, apresentaram temperaturas mais elevadas entre $28^{\circ} \mathrm{C}$ a $30^{\circ} \mathrm{C}$, de forma homogênea refletindo a densidade urbana, a alta impermeabilização e pavimentação asfáltica e coberturas predominante de fibrocimento e alumínio, com a vegetação arbórea esparsa ou inexistente.

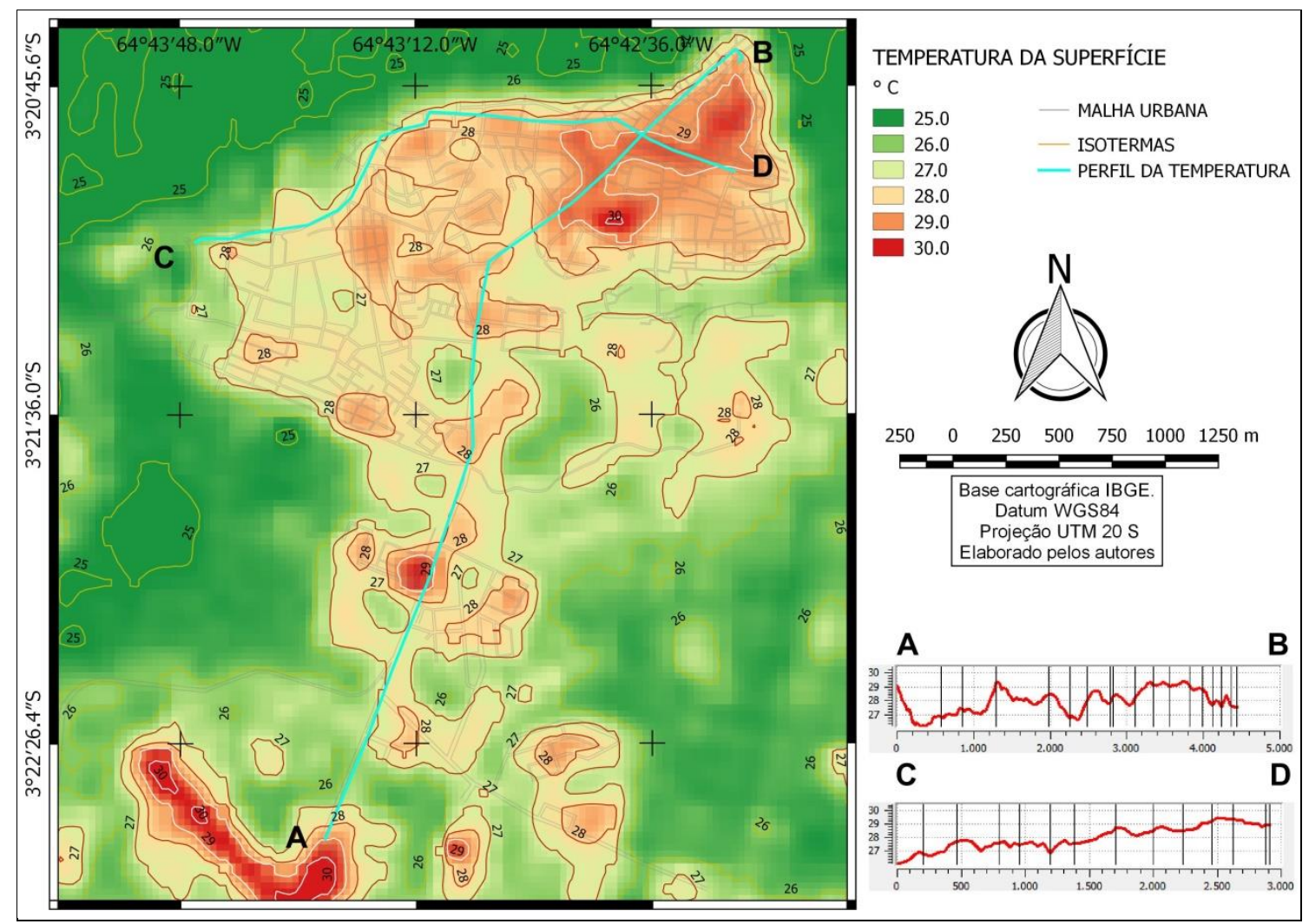

Figura 9. Carta da temperatura da superfície de Tefé, originada a partir do infravermelho termal do satélite Lansat 8 -TIRS no dia 15/06/2015.

Dessa maneira, como a ocupação do solo por esses materiais diminui o albedo e aumenta a capacidade de absorção da radiação ultravioleta, o aquecimento é mais elevado, por isso, verifica-se nessas áreas a configuração das ilhas de calor em superfície.

Nas áreas A e C as temperaturas superficiais são menores, porém, como demonstram a reflectância dos alvos, nos edifícios das vilas militares e na sede do aeroporto que possui parte do telhado de alumínio e solo exposto nas bordas asfalticas da pista a tempetura apresentou-se mais elevada chegando a $30^{\circ} \mathrm{C}$. 
Ressalta-se que na na figura 9, a Área C apresentou os menores valores da temperatura da superfície de maneira uniforme na malha urbana, comparada as demais áreas.

O NDVI apresentou comportamento similar à temperatura superficial, pois, demonstrou a classe de baixa densidade de vegetação principalmente nas Áreas B e D, apresentando valores próximos à -1, na parte central da cidade de Tefé, e maior densidade de vegetação nas Áreas A e C, valores próximos à 1 de acordo com a figura 10.

A área mais densamente construída apresentou valores negativos, próximos à -1, porém, em alguns locais nas Áreas A e C, a presença de materiais construtivos, solo exposto e cultivos agrícolas incipientes, foram responsáveis pelos valores negativos e próximos a 0 .

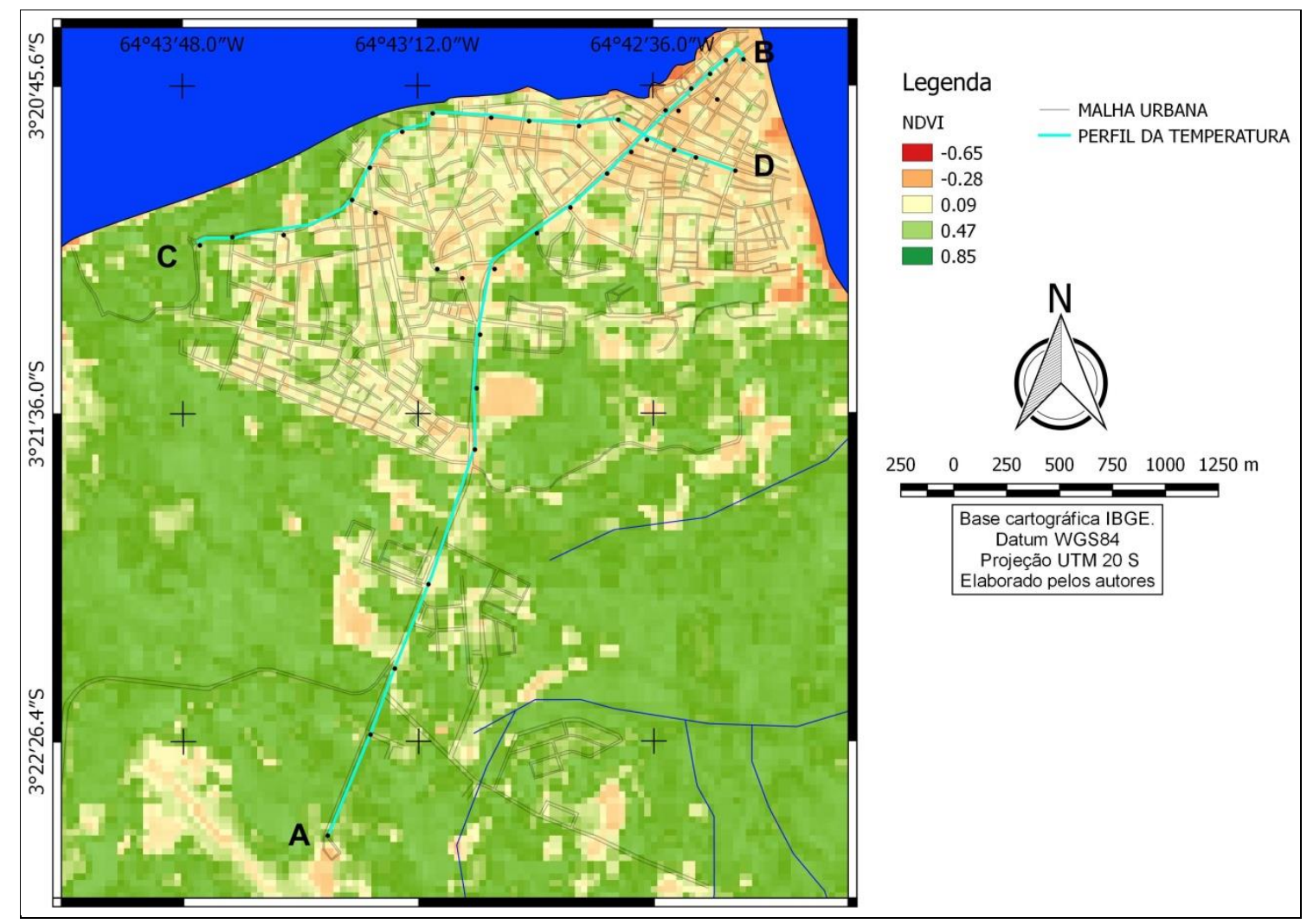

Figura 10. Índice de Vegetação da Diferença Normalizada (NDVI) em Tefé.

A vegetação arbórea tem um papel importante para amenizar a temperatura, pela interceptação da radiação solar, o papel da evapotranspiração, a maior presença de sombreamento e correntes de ventos limpando os poluentes da atmosfera e pode atenuar a magnitude das ilhas de calor. 
As cartas da temperatura do ar, da superfície e o NDVI são representações do contexto urbano de Tefé que se integram na compreensão do campo térmico e das ilhas de calor e confirmam que a população residente e que vivencia as condições sinóticas estáveis nas áreas B e D são mais afetadas pelas ilhas de calor e desconforto térmico, que podem potencializar problemas de saúde como cardiovasculares, respiratórios, desempenho físico, psicossociais, entre outros, nos citadinos.

Portanto, o clima urbano deve ser considerado como pauta de fundamental importância no planejamento urbano nas cidades de porte médio e pequeno na Amazônia Brasileira, pois, mesmo rodeada por área de floresta ombrófila densa, a cidade de Tefé apresentou alterações térmicas derivadas da produção do espaço urbano sem arborização nas calçadas e áreas de lazer de uso público, além da utilização de materiais construtivos inadequados ao clima equatorial, pela baixa capacidade de reflectância da radiação solar.

\section{CONSIDERAÇÕES FINAIS}

As diferenças térmicas no espaço intraurbano de Tefé apontaram a existência de um clima urbano característico e apresentaram a formação das ilhas de calor e frescor relacionadas às áreas de maior aquecimento e de temperaturas amenas na malha urbana.

A intensidade da ilha de calor identificada foi considerada forte nos episódios apresentados, com amplitude de até $4,6^{\circ} \mathrm{C}$ entre os pontos. A área central de mais antiga ocupação e situando-se a margem do rio Tefé apesar do efeito da brisa, obteve as temperaturas mais elevadas, todavia, a estrada do aeroporto ao Sul da malha urbana, próxima à floresta primária obteve os menores valores da temperatura do ar, ambas associadas aos diferentes usos e a ocupação do solo.

As temperaturas da superfície variaram de $25^{\circ} \mathrm{C}$ a $30^{\circ} \mathrm{C}$ e também indicaram a concentração do aquecimento na parte central, derivada da ampla cobertura nos edifícios de materiais construtivos como telhados de fibrocimento e alumínio inapropriados para o clima equatorial. Esse fato se associa e 
fortalece a vasta utilização de climatizadores artificiais na malha urbana de Tefé potencializando o consumo energético advindo de usina termelétrica.

As isotermas, a temperatura superficial e o NDVI demonstraram a importância da arborização urbana no entorno dos pontos, pois, a alta densidade de vegetação arbórea atua como fator amenizador da temperatura.

Dessa forma, a cidade apesar de se inserir em área envolta por floresta ombrófila densa considerada como "Amazônia profunda", derivada da produção do espaço sem planejamento urbano adequado às condições físico-naturais e desiguais em múltiplos contextos socioeconômicos, necessita inserir a perspectiva climática em medidas de mitigação e re (produção) do espaço urbano que reflita em condições adequadas ao bem-estar e qualidade de vida da população.

\section{AGRADECIMENTOS}

Ao Conselho Nacional de Desenvolvimento Científico e Tecnológico (CNPq) pelo financiamento da pesquisa no edital Universal 014/2013.

\section{REFERÊNCIAS}

AGUIAR, F.G.O. As alterações climáticas em Manaus no século XX. 1995. 182 f. Dissertação de mestrado em Geografia, Universidade Federal do Rio de Janeiro, Rio de Janeiro, 1995.

AMORIM, M.C.C.T. Intensidade e forma da ilha de calor urbana em Presidente Prudente/SP: episódios de inverno. Revista Geosul, UFSC - Florianópolis, v. 20, n. 39, p.65-82, jan./jun. 2005.

AMORIM M.C.C.T., DUBREUIL V., QUENOL H., SANT'ANNA J.L. Características das ilhas de calor em cidades de porte médio: exemplos de Presidente Prudente (Brasil) e Rennes (França). Confins, Online, 7, 16p., 2009.

AMORIM, M.C.C.T. Clima urbano: estrutura térmica e ilhas de calor. In.: AMORIM, M.C.C.T.; SANT'ANNA NETO, J.L.; MONTEIRO, A. (Orgs.). Climatologia urbana e regional: questões teóricas e estudos de caso. 1 ed. São Paulo: Outras expressões, 2013.

ARAÚJO, A.P.; ALEIXO, N. C.R.; MENEZES, B.B.; SOUZA, C. G.; RIVERO, C.A.V.; MONTEZANI, E.; BRAIDO, L.M. H.; AMORIM, M. C. C. T. Ensaio metodológico sobre a utilização de transectos móveis no período diurno em Presidente Prudente/SP. Formação (Presidente Prudente), v. 1, p. 77-95, 2010.

CORRÊAA, P. B.; CÂNDIDO, L. A.; SOUZA, R. A. F.; ANDREOLI, R. V. KAYANO, T. M. Estudo do Fenômeno da Ilha de Calor na Cidade de Manaus/AM: Um Estudo a Partir de Dados de Sensoriamento Remoto, Modelagem e Estações Meteorológicas. Revista Brasileira de Meteorologia, v. 31, n. 2, 167-176, 2016. 
INSTITUTO BRASILEIRO DE GEOGRAFIA E ESTATÍSTICA (IBGE). Cidades-informações, censo (2010). Disponível em: www.ibge.gov.br/cidades. Acesso em: 10 de junho de 2014.

FERNANDEZ GARCÍA. F. Manual de climatologia aplicada: clima, medio ambiente y planificación.

Madrid:Editorialsíntesis, S.A., 1996. 285p.

FIALHO, E. S. Ilha de calor em cidade de pequeno porte: Caso de Viçosa, na Zona da Mata Mineira. 248f. Tese (Doutorado em Geografia Física), Faculdade de Filosofia, Letras e Ciências Humanas, Programa de Pós-graduação em Geografia Física, USP, 2009.

FIALHO, E. S. A pesquisa climatológica realizada por geógrafos brasileiros. Revista brasileira de climatologia, ano 6 , v 6 , Junho/ 2010, p. 193-212.

FIALHO, E. S. Ilha de calor: reflexões acerca de um conceito. ACTA Geográfica, Boa Vista, Ed. Esp. Climatologia Geográfica, 2012. p. 61-76.

FIALHO, E. S.; CELESTINO, E. J.; QUINA, R. R. O campo térmico em situação episódica de primavera em uma cidade de pequeno porte, na zona da mata mineira: um estudo de caso em Cajuri-MG. Revista de Geografia (Recife), v. 33, n. 4, 2016, p. 299-318.

FISCH, G.; MARENGO, J. A.; NOBRE, C. A. Uma revisão geral do clima da Amazônia. Acta Amazônica, v.28, n. 2, p. 101-126, 1998.

KOUSKY, V.E. e KAGANO, M.T. A climatological study of the tropospheric circulation over the Amazon region. Acta Amazônica, v. 11, n. 4: 743 - 758, 1981.

LONGLEY, P. A. GOODCHILD, M. F. MAGUIRE, D. J. RHIND, D.W. Sistemas e ciência da Informação geográfica. $3^{\text {a }}$ ed. Porto Alegre: Bookman. 2013.

MARENGO, J.A; NOBRE, C. (2009). Clima da região Amazônica. In.:Tempo e Clima no Brasil. Cavalcanti, I. et al. (Orgs.) São Paulo: Oficina de Textos, p.197-207, 2009.

MENDONÇA, F.; DANNI - OLIVEIRA, I. M. Climatologia: noções básicas e climas do Brasil. São Paulo: Oficina de textos, 2007.

MENDONÇA. F. O estudo do SCU - Sistema do Clima Urbano - no Brasil: Aplicações e avanços. In: Carlos Augusto Figueiredo Monteiro et al. (Org.). A construção da climatologia geográfica no Brasil. 1ed.Campinas. SP: Alínea Editora, 2015 , v. 1, p. 155-166.

MOLION, L.C.B. Climatologia Dinâmica da região Amazônica: mecanismos de precipitação. Revista Brasileira de Meteorologia, v. 2, n. 1, p.107 - 117, 1987.

MONTEIRO, C.A.F. Teoria e Clima Urbano. São Paulo: Universidade de São Paulo, Instituto de Geografia, 1976.

OKE, T. R. Boundary layer climates. 2nd ed. London: Methuen, 1987.

ORTIZ PORAnGABA, G. F. 0 clima urbano das cidades do interior do estado de São Paulo: uma análise do campo térmico de Assis, Cândido Mota, Maracaí e Tarumã. 354f. Tese (Doutorado em Geografia) - Faculdade de Ciências e Tecnologia, Universidade Estadual Paulista, Presidente Prudente, 2015.

PEREIRA VIANA, L. et al. Ilhas de calor na cidade de Manaus: um estudo observacional e de modelagem numérica. Revista Geonorte, v. 3, n. 9, p. 1387-1396, 2012. 
PITTON, S. E. C. As cidades como indicadores de alterações térmicas. 272p. Tese (Doutorado em Geografia Física) Faculdade de Filosofia, Letras e Ciências Humanas, Universidade de São Paulo, São Paulo, 1997.

SCHOR, T.; OLIVEIRA, J.A. Reflexões metodológicas sobre o estudo da rede urbana no Amazonas e perspectivas para a análise das cidades na Amazônia brasileira. ACTA Geográfica, Ed. Esp. Cidades na Amazônia Brasileira, 2011, p.15-30.

SILVA, D.A.; AGUIAR, F.E. Ilha de calor na cidade de Manaus: especulação ou realidade? Revista Geonorte, v.1, n.6, p.49-65, 2012.

UGEDA JUNIOR, J. C. Clima urbano e planejamento na cidade de Jales/SP. 383 f. Tese (Doutorado em Geografia) Faculdade de Ciências e Tecnologia, Universidade Estadual Paulista, Presidente Prudente, 2012.

UNITED State GEOLOGICAL SURVEY USGS. Using the USGS Landsat Level-1 Data Product. Website: https://landsat.usgs.gov/Landsat8_Using_Product.php. Acessado em 04 de abril de 2018.

VIANA, V. M.. Bolsa Floresta: um instrumento inovador para a promoção da saúde em comunidades tradicionais na Amazônia. Revista de estudos avançados, vol.22, n.64, p.143-153, 2008. 